\title{
Influência da variação dos parâmetros de compactação de solos da região do Cariri
}

\author{
Influence of the variation of soil compaction parameters of the Cariri region
}

\author{
Antonio Júnior Alves Ribeiro \\ Instituto Federal de Educação, Ciência e Tecnologia do Ceará \\ E-mail: ajar.junior@gmail.com
}

Carolaine da Silva Landim Cruz Instituto Federal de Educação, Ciência e Tecnologia do Ceará

E-mail: carolainecruz17@gmail.com

Wana Maria de Souza Instituto Federal de Educação, Ciência e Tecnologia do Ceará E-mail: wanamaria19@gmail.com

Recebido em: 23/05/2018 | Aceito em:28/06/2018

\section{RESUMO}

O presente estudo teve por objetivo analisar a influência da variação de parâmetros de camadas e volume de cilindro de compactação com ensaios manuais realizados em laboratório, com dois solos da região do Cariri, sendo um solo fino e outro grosso. Para tanto, tomou-se como referência o ensaio executado em cinco camadas e aplicados doze golpes por camada, em um cilindro com volume de $2095,93 \mathrm{~cm}^{3}$, realizando compactação em três e sete camadas, modificando também o volume do cilindro para $1570,80 \mathrm{~cm}^{3} \mathrm{com}$ estrutura repartida. Com base nos resultados obtidos, pode-se concluir que não há diferença entre o método normal e as variações realizadas, sendo a diferença máxima inferior a $2 \%$, para ambos os solos, que houve variação capaz de conferir massa específica máxima superior ao método normal de referência com uma umidade menor para o solo 1, que para o solo 2, a compactação realizada pelo procedimento normatizado conferiu melhor massa específica em relação às variações feitas, ainda pode-se observar que é 
possível trabalhar com umidades menores, sem relevante diminuição da massa especifica máxima do solo, o que acarreta em economia de água e dos custos. O estudo foi importante, pois estimulou uma pesquisa em laboratório, além de abrir percepções sobre a compactação, visto que os resultados obtidos são importantes para um futuro trabalho em aterros.

Palavras Chave: Compactação. Massa específica máxima. Umidade. Camadas. Cilindro.

\section{ABSTRACT}

The present study had the objective of analyzing an influence of the variation of layers parameters and volume of compaction cylinder with manual tests performed in the laboratory, with two soils of the Cariri region, being a thin and one coarse soil. For this purpose, the test was carried out in five layers and applied in a volume of $2095.93 \mathrm{~cm}^{3}$, making compression in three and seven layers, also modifying the cylinder volume to $1570,80 \mathrm{~cm}^{3}$ with distributed structure. Based on the obtained results, it can be concluded that statistically, there is no difference between the normal method and the variations performed, that there was variation capable of conferring a maximum specific mass higher than the normal reference method with a minority, for soil 1 , for soil 2 , the compaction performed by the standardized procedure gave a better specific mass in relation to the variations made, it is still observerd that is possible to work with smaller dampers, without prejudice to the specific mass of the soil, which results in water savings and cost. The study was extremely important, it stimulated a laboratory research, as well as open perceptions about a compaction, since the obtained results are important for a future work in landfills.

KEYWORDS: Compaction. Specific maximum mas. Moisture. Layers. Cylinder.

\section{INTRODUÇÃO}

Para trabalhos com fins geotécnicos e/ou construtivos, muitas vezes o solo local pode apresentar condições insuficientes para o desenvolvimento dessas atividades. Ele pode ser muito compressível, pouco resistente, muito permeável, com características que inviabilizam economicamente o empreendimento. Assim, é necessária a realização de alguns processos que melhorem suas propriedades, como a compactação, que confere a estabilização do solo pela redução do volume de vazios contidos em seus poros.

A compactação é um método utilizado para proporcionar o aumento da união entre os grãos, tornando o solo mais homogêneo e estável, e se dá pela aplicação de uma energia (dinâmica, estática, por vibração ou por pisoteamento) que promove o aumento no peso específico seco do solo, diminuição da permeabilidade, Ciência e Sustentabilidade - CeS / Juazeiro do Norte, v. 4, n. 1, p. 156-177, jan/jun - 2018 
compressibilidade e do índice dos vazios. A massa específica seca aumenta em função do teor de umidade em que o solo estiver, atingindo seu ponto máximo e passando a decrescer. Na inflexão do gráfico que é obtido, encontra-se a ordenada massa específica máxima e umidade ótima. Aumentando-se a energia de compactação, obtém-se umidade menor e densidade máxima maior (PEREIRA JUNIOR et al., 2016).

Um dos ensaios mais utilizados no processo de compactação dos solos é o de Proctor, importante para o estudo e controle da qualidade de aterros de solos compactados. Em laboratório de solos, os ensaios mais comumente realizados são os de Proctor na energia normal, Proctor na energia intermediária e Proctor na energia modificada, que se enquadram na categoria da compactação dinâmica.

Quando se trata de compactação, um dos fatores relevantes é a umidade ótima necessária para alcançar a massa específica máxima de determinado solo. É a umidade que determinará a quantidade de água que será utilizada na compactação em campo (PEREIRA JUNIOR et al., 2016).

Em se tratando de água, uma das questões de maior preocupação é a sua escassez. Com a seca prevalente maior parte do ano na região do semiárido nordestino, a economia de água se torna um fator que merece atenção, visto que dela depende o abastecimento humano, a dessedentação animal, a irrigação, a indústria e as demais necessidades dos seres vivos.

Para tanto, é importante o estudo de novas técnicas para a racionalização da água, em especial na construção civil, indústria que consome considerável quantidade em suas atividades.

Este trabalho teve como finalidade estudar variações no método de compactação com energia normal, determinando, então, a técnica de compactar que possibilita o uso de menos água na compactação em campo, através da redução da umidade ótima, sem relativa diminuição da massa específica seca máxima do solo estudado. 


\section{REVISÃO BIBLIOGRÁFICA}

\subsection{A Compactação}

A compactação pode ser definida como um processo mecânico baseado na expulsão do ar presente nos poros do solo, pelo qual uma compressão é exercida sobre o mesmo com uma dada energia mecânica, com o objetivo de melhorar as propriedades do material compactado através da redução do índice de vazios, sem alterações no seu teor de umidade ou massa, porém, modificando sua estrutura e propriedades originais (CRISPIM,2007, SOUZA JUNIOR, 2005). Para Pinto (2006), a compactação tem como grandes aspectos, aumentar a intimidade entre os grãos e mudar a estrutura do solo, tornando-o mais homogêneo, como forma de melhorar as características de resistência, deformabilidade e permeabilidade.

A especificação 108/2009 regida pelo Departamento Nacional de Infraestrutura de Transporte (DNIT) define compactação como "operação por processo manual ou mecânico, destinada a reduzir o volume de vazios de um solo ou outro material, com a finalidade de aumentar-Ihe a massa específica, resistência e estabilidade".

Crispim (2010) sugere ainda uma definição mais precisa do que é o processo de compactação: "pode ser definido, basicamente, como a redução de seu índice de vazios, sob ação de uma força mecânica, havendo reacomodação da sua fase sólida e variação na sua fase gasosa, mas sem perda da fase líquida".

Souza Junior (2005) e Mitchell (1964, apud Werk, 2000) afirmam que a compactação confere ainda outros benefícios quanto às propriedades geotécnicas do solo, quais são: aumento da densidade, controle de tendência de variação volumétrica, aumento da resistência ao cisalhamento, aumento da capacidade de suporte, controle de propriedades resilientes, redução da permeabilidade, redução da contração e redução da compressibilidade.

Segundo Crispim (2010), os primeiros trabalhos realizados a fim de padronizar a técnica de compactação aconteceram nas primeiras décadas do século $X X$. Um dos mais importantes pesquisadores era o engenheiro norte americano Ralph R. Proctor, que publicou seus estudos sobre a compactação de aterros do solo em 1933 nos Estados Unidos da América, padronizando, então, esse ensaio. 
Essa técnica passou a ser conhecida como Ensaio de Proctor, sendo normatizado no Brasil pela ABNT (NBR 7182/1986) e DNIT (DNER, 1994).

Em seu estudo, Proctor (1933) demonstrou que, ao submeter o solo a uma compressão em uma determinada energia de compactação com certo número de passadas (golpe) de equipamento, a massa específica resultante é função da umidade do solo no momento da compressão. Proctor (1933) percebeu que, a massa específica seca do solo aumenta juntamente com o teor de umidade até chegar num valor máximo, a partir do qual passa a decrescer. Assim, ele concluiu que, para cada energia de compactação, há uma umidade ótima que propiciará uma compactação máxima, com um valor de massa específica máxima. Logo, se a água utilizada na compactação for maior ou menor que a umidade ótima, o solo não atingirá seu grau de compactação máxima.

Segundo Pinto (2006) na compactação, as quantidades de partículas e de água permanecem constantes; o aumento da massa especifica corresponde à eliminação de ar dos vazios. A saída do ar é facilitada porque, quando a umidade não é muito elevada, o ar se encontra em forma de canalículos intercomunicados. A redução do atrito pela água e os canalículos permitem uma massa específica maior quando o teor de umidade é maior.

Pinto (2006) ainda afirma que, quando é realizado o processo de compactação com uma umidade baixa, o atrito entre as partículas do solo é muito alto, o que impede que se obtenha uma considerável diminuição dos vazios.

\subsection{Métodos de Compactação}

A compactação é utilizada para vários fins, como, por exemplo, aterros, construção de barragens, camadas de construção dos pavimentos. Para tanto, existem vários tipos de técnicas de compactar. As mais utilizadas em laboratório são: compactação estática ou por pressão, compactação por pisoteamento ou por amassamento, compactação por vibração e compactação dinâmica ou por impacto.

Pinto (2006) explica que para escolher o melhor método, é necessário conhecer o tipo de obra e de solo disponível, bem como a umidade em que se encontra e a densidade que se deseja. Ele ressalta que a escolha do processo correto tem como finalidade reduzir a permeabilidade do solo, evitar futuros 
recalques, aumentar a rigidez e a resistência do solo. A seleção do método mais adequado a ser utilizado depende da escolha da energia que reproduza melhor 0 que se espera em campo.

Quintans (2008) ressalta a importância da técnica correta exemplificando que, para compactação de solos granulares, o melhor a ser empregado é o método de vibração, já que permite um rearranjo maior dos grãos com menos vazios. Já para solos finos, a compactação por amassamento proporciona uma reprodução mais próxima da compactação feita em campo. Ele ainda menciona que, embora o método de compactação por impacto não seja o mais adequado, é aceito para fins rodoviários, atendendo às variações em relação aos processos construtivos.

\subsubsection{Ensaios de Compactação Estática ou por Pressão}

A técnica de compactação estática foi implementada por Porter por volta dos anos 1930 e consiste na aplicação de uma pressão constante e uniformemente distribuída sobre o solo, buscando representar precisamente, em laboratório, as características de solos granulares compactados em campo. Nesse método, cada camada de amostra de solo é compactada com uma prensa, sujeita a uma pressão determinada durante um certo tempo. A energia específica de compactação varia de acordo com o tamanho do molde, da intensidade da pressão e do tempo de aplicação desta (WERK, 2000).

\subsubsection{Ensaios de Compactação por Pisoteamento ou por Amassamento}

Indicado para solos coesivos, esse método consiste na aplicação sucessiva de altas pressões que variam com o tempo de forma crescente e decrescente, ciclicamente, sobre pequenas áreas de uma amostra de solo, através de um sistema composto por uma haste em barra de metal pelo qual uma peça cilíndrica é pressionada verticalmente no sentido da amostra e os agregados do solo são desmanchados (SOBREIRA, 2014). Nesse processo, é utilizado um compactador mecânico desenvolvido por Hveem em 1955, que independe da força humana e opera reproduzindo o comportamento do solo compactado em campo com o uso de um pé-de-carneiro. A energia de compactação varia conforme a pressão aplicada, 
tamanho do molde, número de aplicações e características do sistema de pressão (BALMACEDA, 1991, apud WERK, 2000). Esse método é o que introduz maiores tensões de cisalhamento, representando melhor as condições de campo quando realizado com pé-de-carneiro.

\subsubsection{Ensaios de Compactação por Vibração}

O método de compactação por vibração é mais indicado para solos granulares, apresentando resultados mais precisos do que a compactação por impacto em tais solos. Os ensaios são realizados pela vibração de um molde cilíndrico, como o de Proctor, sobre uma mesa ou placa vibratória. Pode ser colocada ainda uma sobrecarga sobre a amostra de solo. A frequência, amplitude, aceleração da mesa vibratória, sobrecargas, granulometria e teor de umidade podem influenciar nesse método (SOUZA JUNIOR, 2005).

\subsubsection{Ensaios de Compactação Dinâmica ou por Impacto}

Método caracterizado pela ação da queda de um soquete sobre a camada de solo presente no molde. O ensaio de compactação dinâmica mais utilizado é o de Proctor (1933), normatizado pela AASHTO (American Association of State Highway and Transportation Officials) dos Estados Unidos da América. Esse método ficou conhecido como Ensaio Proctor Normal. No Brasil, é regido pela ABNT NBR 7182/86 "Solo - Ensaio de Compactação" e pelo DNIT, DNER-ME 129/94 "Solos compactação utilizando amostras não trabalhadas".

Segundo Souza Junior (2005), Proctor desenvolveu esse ensaio para determinar, através de uma curva de compactação, que a massa específica varia em função da umidade do solo, como se pode observar Tabela 1.

Em seus estudos, Proctor (1933) observou que no ramo seco, em que a curva é ascendente, o atrito entre grãos é reduzido gradativamente, à medida que o teor de umidade aumenta. No ramo úmido, onde a curva passa a decair, a água contida no solo não mais permite que o ar seja expulso pela compactação, pois o grau de saturação já é elevado, passando a ter mais água do que partículas de solo e a massa específica decresce. Onde há a inflexão da curva, este é o ponto em que o 
solo atinge sua massa específica aparente seca máxima (үdmáx), e é determinada sua umidade ótima (Wót).

Solos diferentes, quando compactados com a mesma energia, podem apresentar curvas de compactação diferentes. Comparada à argila, por exemplo, a areia possui massa específica máxima maior e menor umidade ótima, tendo seu ponto de massa específica máximo mais bem definido, como se pode observar nas Figuras 1 e 2.

Figura 01: Massa Específica Seca Máxima (ydmáx) e Umidade Ótima (Wót) referentes à curva de compactação.

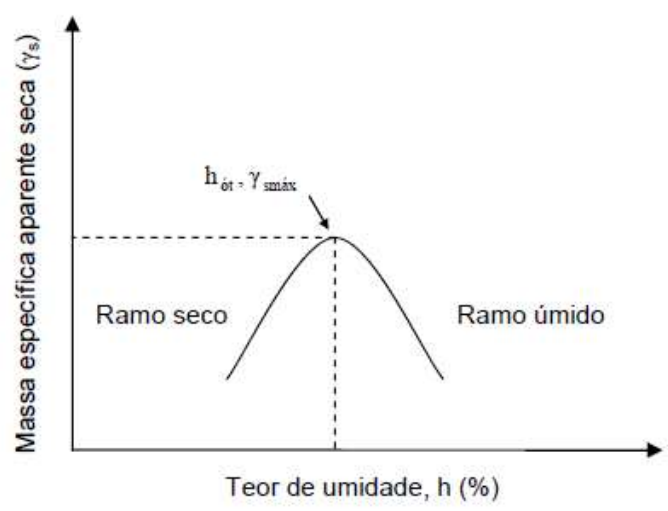

FONTE: CRISPIM (2007).

Figura 02: Influência do tipo de solo na curva de compactação.

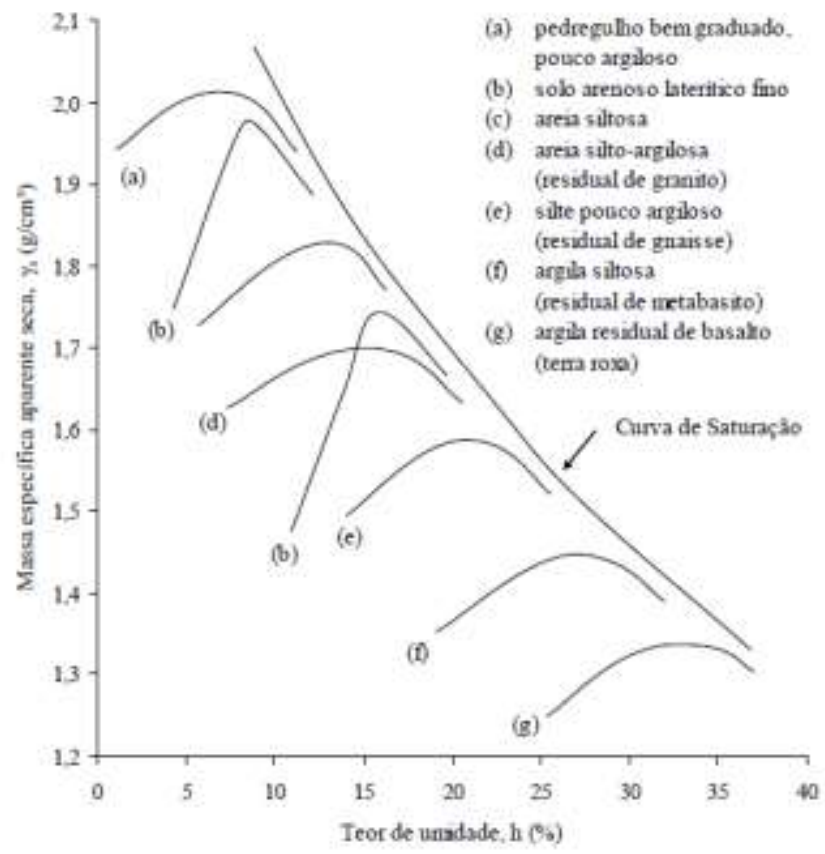

FONTE: CRISPIM (2007). 
O Ensaio Normal de Compactação (ABNT NBR 7182/86) consiste em compactar uma amostra de solo confinada num molde cilíndrico padrão, aumentando de forma gradual a umidade. A compactação é feita por camada, aplicando-se golpes por camada com um soquete de peso padronizado, caindo de uma altura fixa. Esses parâmetros dependerão da energia de compactação (ver Equação 1) definida, como é representado na Tabela 1.

TABELA 1: Energias de compactação.

\begin{tabular}{ccccc}
\hline \multirow{2}{*}{ Cilindro } & $\begin{array}{l}\text { Características inerentes a } \\
\text { cada energia de compactação }\end{array}$ & Normal & Intermediária & Modificada \\
\cline { 3 - 5 } & Soquete & Pequeno & Grande & Grande \\
\cline { 2 - 5 } Pequeno & Número de camadas & 3 & 3 & 5 \\
& $\begin{array}{c}\text { Número de golpes por } \\
\text { camada }\end{array}$ & 26 & 21 & 17 \\
& Soquete & Grande & Grande & Grande \\
\cline { 2 - 5 } Grande & $\begin{array}{c}\text { Número de camadas } \\
\text { Número de golpes por }\end{array}$ & 5 & 5 & 5 \\
& camada & 12 & 26 & 55 \\
& Altura do disco espaçador & 63,5 & 63,5 & 63,5 \\
\hline
\end{tabular}

FONTE: ABNT NBR 7182 - Ensaio de compactação

$$
E=\frac{n \cdot N \cdot P \cdot H}{V}
$$

Onde:

n: número de golpes por camada;

$\mathrm{N}$ : número de camadas;

$\mathrm{P}$ : peso do soquete $(\mathrm{kgf})$;

$\mathrm{H}$ : altura de queda do soquete $(\mathrm{cm})$;

V: volume do molde cilíndrico $\left(\mathrm{cm}^{3}\right)$.

\section{METODOLOGIA}

\section{Solos}

Para a realização dos ensaios, foram selecionados dois solos distintos (Figura 1a e 1b). O solo com característica silto-arenoso de cor avermelhada, aqui denominado Solo 1, o qual foi coletado no município de Barbalha-CE. com coordenadas $7^{\circ} 19^{\prime} 52.75^{\prime \prime S}$ e 39॰17'37.28"O. O solo 2, com característica arenoso e de coloração acinzentado, foi coletado do Geossítio Colina Horto do Padre Cícero, 
localizado em Juazeiro do Norte-CE com coordenadas $7^{\circ} 10^{\prime 2} 26.85$ "S e 39॰19'45.91"O.

Figura 03: Solos utilizados na pesquisa.

FONTE: Autores.

A escolha dos solos deu-se pelo fato de serem materiais comumente utilizados na região, sendo o solo 1 facilmente encontrado e empregado em $80 \%$ da região do Cariri, e o solo 2 ser bastante utilizado na cidade de Juazeiro do Norte.

\subsubsection{Ensaios de Caracterização Física}

Para a realização dos ensaios de propriedades físicas, as amostras dos solos foram preparadas como descrito na DNER - ME 041/94 - Solos - preparação de amostras para ensaios de caracterização. Os ensaios realizados foram: análise granulométrica por peneiramento e densidade real dos grãos.

A análise granulométrica por peneiramento é um procedimento realizado para a determinação da percentagem retida em cada faixa de tamanho de partículas da massa total ensaiada (DNER - ME 080/94). A amostra de cada material é separada, pesada e levada às peneiras que estão sobrepostas de forma sequencial de abertura de malha (Figura 4) e em seguida, ao peneirador mecânico para fazer o agitamento das peneiras durante quinze minutos. Com os resultados, obtém-se a curva de distribuição granulométrica, determinando a faixa de grãos mais significativo para a classificação do solo. 
FIGURA 04: Conjunto de peneiras para ensaio de granulometria.

FONTE: Autores.

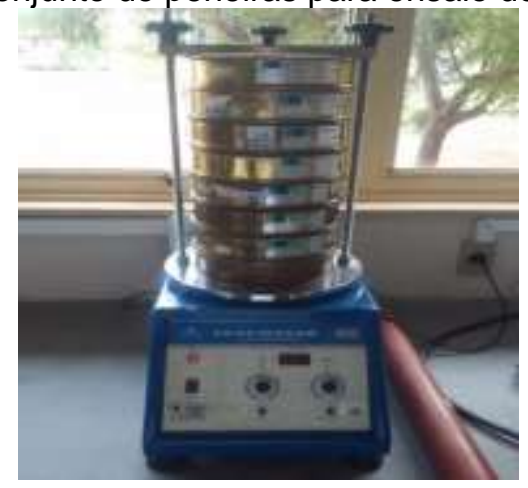

O ensaio de densidade real tem como objetivo determinar a massa específica dos grãos do solo de uma amostra (DNER - ME 093/94). A amostra de solo é colocada em um picnômetro (Figura 5) e coberta por água destilada e levada ao bico de gás ou outra fonte de calor e fervida por 15 minutos, a fim de expulsar todo o ar existente entre as partículas. Em seguida, o picnômetro é preenchido por água destilada e levado ao equipamento de banho maria em temperatura ambiente por 15 minutos. Após esse período, o material é retirado do picnômetro e o recipiente é levado ao banho maria, desta vez, apenas com água destilada. A densidade real dos grãos é determinada pela média de duas determinações, no mínimo, não diferindo 0,009 entre elas (DNER-ME 093/94).

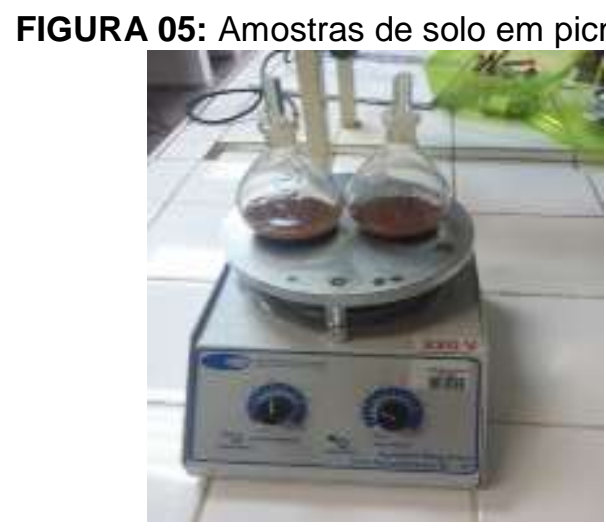

FONTE: Autores.

\subsubsection{Ensaios de caracterização mecânica}

Para o ensaio de caracterização mecânica foi realizada a compactação manual com Energia de Proctor Normal utilizando amostras trabalhadas (DNER-ME 
162/94). O ensaio Normal consiste em preencher o cilindro de aproximadamente $2000 \mathrm{~cm}^{3}$ com coroa complementar (Figura 4) com solo dividido em 3 camadas, aplicando-se 12 golpes por camada com um soquete de $4,5 \mathrm{~kg}$ caindo de uma altura de $45 \mathrm{~cm}$. Em seguida, faz-se o arrasamento do solo que fica na coroa complementar até altura do cilindro principal, levando em seguida à balança. Logo após, amostras do solo são retiradas para cada umidade em que o solo é compactado e levadas à estufa numa temperatura de $105 \pm 5^{\circ} \mathrm{C}$ por, no mínimo, 24 horas. A umidade é acrescentada de 2 em $2 \%$, até que o peso do cilindro preenchido por solo decaia. Nesse momento, a massa específica seca já alcançou seu ponto máximo. Com os resultados do ensaio, obtém-se o gráfico com o ponto máximo da curva, que representa a massa específica seca máxima do solo compactado, determinando, então, a umidade ótima.

FIGURA 06: Cilindro para Ensaio Normal de Proctor.

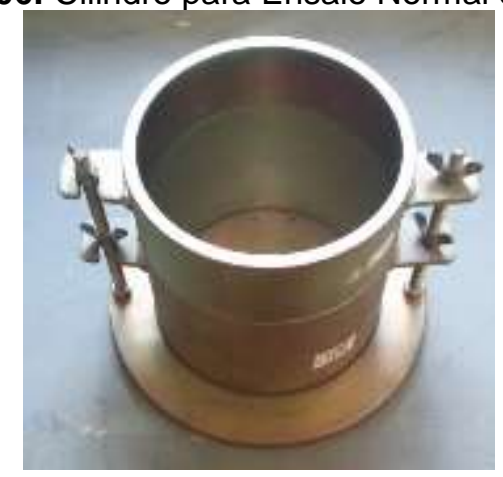

FONTE: Autores.

$\mathrm{Na}$ Tabela 2 têm-se todas as variações realizadas no ensaio de compactação, bem como o ensaio normatizado.

TABELA 02: Variações no número de camadas e golpes para ensaio de compactação.

ENERGIA: $5,80 \mathrm{~kg} . \mathrm{cm} / \mathrm{cm}^{3}$; PESO DO SOQUETE: $4,5 \mathrm{~kg}$; ALTURA DE QUEDA: $45 \mathrm{~cm}$

\begin{tabular}{ccc}
\hline VOLUME DO CILINDRO $\left(\mathrm{cm}^{3}\right)$ & NÚMERO DE CAMADAS & $\begin{array}{c}\text { NÚMERO DE } \\
\text { GOLPES }\end{array}$ \\
\hline CBR $=2095,93$ & 5 & 20 \\
& 5 & 12 \\
REPARTIDO= 1570,80 & 3 & 9 \\
\hline
\end{tabular}

Ciência e Sustentabilidade - CeS / Juazeiro do Norte, v. 4, n. 1, p. 156-177, jan/jun - 2018 
FONTE: Autores.

Os valores de 3 e 7 camadas foram determinados a fim de analisar o resultado com camadas abaixo e acima do número estabelecido em norma para a energia escolhida. De semelhante modo acontece com o cilindro, aplicando-se um molde cilíndrico com volume menor, com a finalidade de observar o efeito da compactação nos solos com esse novo cilindro, sem modificar a energia aplicada, possibilitando, então, o uso de um cilindro diferente do determinado nas especificações técnicas para ensaios de laboratório.

Para efeito de variação, os valores de Energia, peso do soquete e altura de queda do soquete foram mantidos fixos. Sendo assim, para variar as camadas no cilindro CBR, o volume também foi fixado, ficando os valores de número de camadas e golpes como variáveis. Determinando, então, o número de camadas sendo 3 e 7 , tem-se como resultado o número de golpes, a fim de manter constante a energia de compactação. Para a variação no cilindro Repartido, o volume foi variado para $1570,8 \mathrm{~cm}^{3}$, permanecendo fixos a Energia, altura de queda e peso do soquete. Sendo assim, determinou-se então, que os números de camadas fossem 3, 5 e 7, mesmos valores realizados no cilindro CBR, a fim de manter mais coesa a comparação dos métodos. Dessa forma, tem-se como consequência da equação, o número de golpes, de modo que a energia se mantenha constante.

O cilindro utilizado para realizar a variação de diâmetro é utilizado como molde de corpos de prova para ensaio de rompimento e verificação de resistência característica do concreto com volume de $1570,80 \mathrm{~cm}^{3}$ e estrutura repartida, com coroa complementar (Figura 7).

FIGURA 07: Cilindro Repartido de 1570,80 cm$^{3}$ utilizado no ensaio de variação.

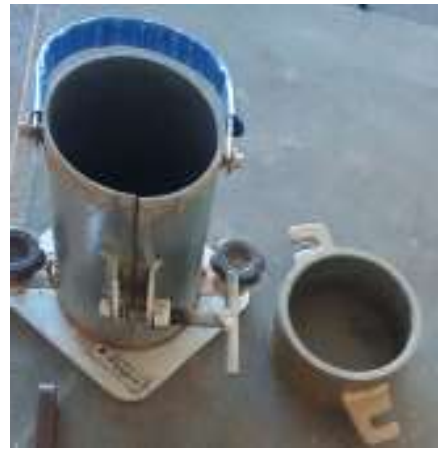

FONTE: Autores. 


\section{RESULTADOS E DISCUSSÕES}

Após a realização dos ensaios de propriedades físicas dos solos, foi possível classificá-los de acordo com os parâmetros de índices da SUCS e AASHTO, determinando qual o material predominante em cada tipo de solo, como mostrado na Tabela 3.

TABELA 03: Caracterização física e mecânica dos solos

\begin{tabular}{|c|c|c|c|}
\hline \multirow{2}{*}{\multicolumn{2}{|c|}{ ENSAIO DE CARACTERIZAÇÃO }} & \multicolumn{2}{|c|}{ SOLOS } \\
\hline & & \multirow{2}{*}{$\begin{array}{c}1 \\
\mathrm{NP}\end{array}$} & \multirow{2}{*}{$\begin{array}{c}2 \\
N P\end{array}$} \\
\hline Limite de Liquidez (\%) & & & \\
\hline Índice de Plasticidade (\%) & & NP & NP \\
\hline Massa Específica dos grãos (g/cm³) & & 2,64 & 2,72 \\
\hline \multirow{5}{*}{ Granulometria (\% retida) } & Argila e silte $(\mathrm{g}<0,06 \mathrm{~mm})$ & 2 & 4 \\
\hline & Areia Fina $(0,06<\mathrm{g}<0,2)$ & 10 & 1 \\
\hline & Areia Média $(0,2<\mathrm{g}<0,6)$ & 66 & 10 \\
\hline & Areia grossa $(0,6<\mathrm{g}<2,0 \mathrm{~mm})$ & 18 & 50 \\
\hline & Pedregulho Fino $(2,0<\mathrm{g}<6,0 \mathrm{~mm})$ & 4 & 35 \\
\hline \multirow{2}{*}{ Classificação de Solos } & SUCS & \multicolumn{2}{|c|}{$\begin{array}{l}\text { Areias bem } \\
\text { graduada }\end{array}$} \\
\hline & AASHTO & \multicolumn{2}{|c|}{$A-1-b$} \\
\hline
\end{tabular}

FONTE: Autores.

Pela caracterização do SUCS e da AASHTO, ambos os solos se enquadram no mesmo grupo, sendo definidos como areias bem graduadas, apresentando curvas granulométricas contínuas, com amostra predominante de areia média e areia grossa nos solos 1 e 2, respectivamente. A Figura 8 mostra as curvas de granulometria dos solos estudados. 
Figura 08: Curvas Granulométricas dos Solos Estudados.

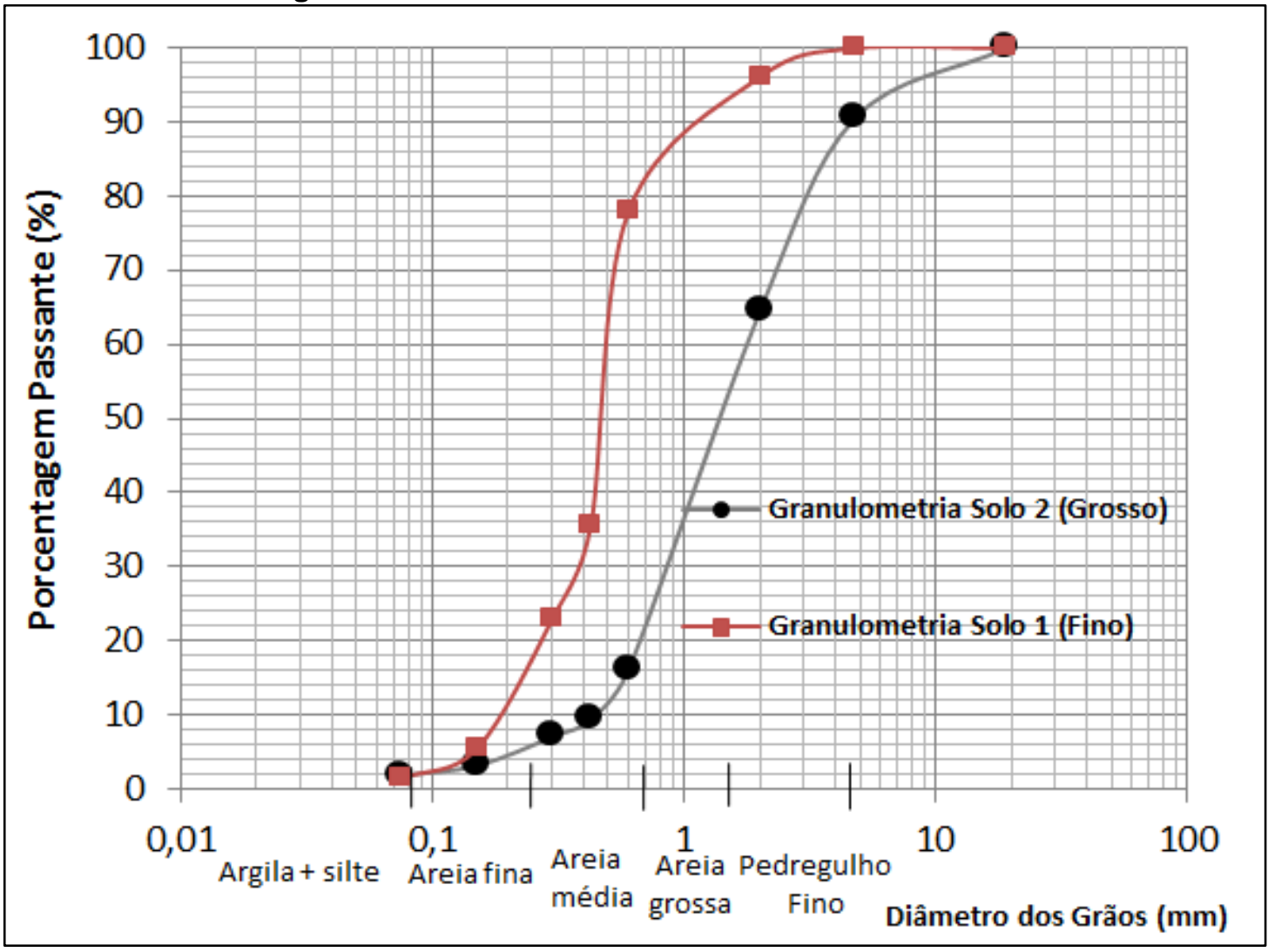

FONTE: Autores.

Percebe-se que no solo 2, além da predominância de solo grosso que caracteriza o material, há ainda preeminência da faixa de grãos de pedregulho fino.

$\mathrm{Na}$ caracterização mecânica realizada pelo ensaio de compactação, foi possível obter as curvas de compactação, com os referidos valores de massa específica e teor de umidade para cada variação. O ensaio Normal foi executado em conformidade com a norma DNER-ME 162/94, que estabelece a realização do procedimento em 5 camadas, e aplicados em cada uma, 12 golpes. Esse método é o parâmetro para a comparação com as variações realizadas no ensaio.

As curvas de compactação são apresentadas nas Figuras 9, 10, 11 e 12, para tanto foram dispostas pelo tipo de cilindro e material utilizados nos ensaios de compactação. 
Figura 09: Curvas de compactação no Cilindro CBR - Solo 1.

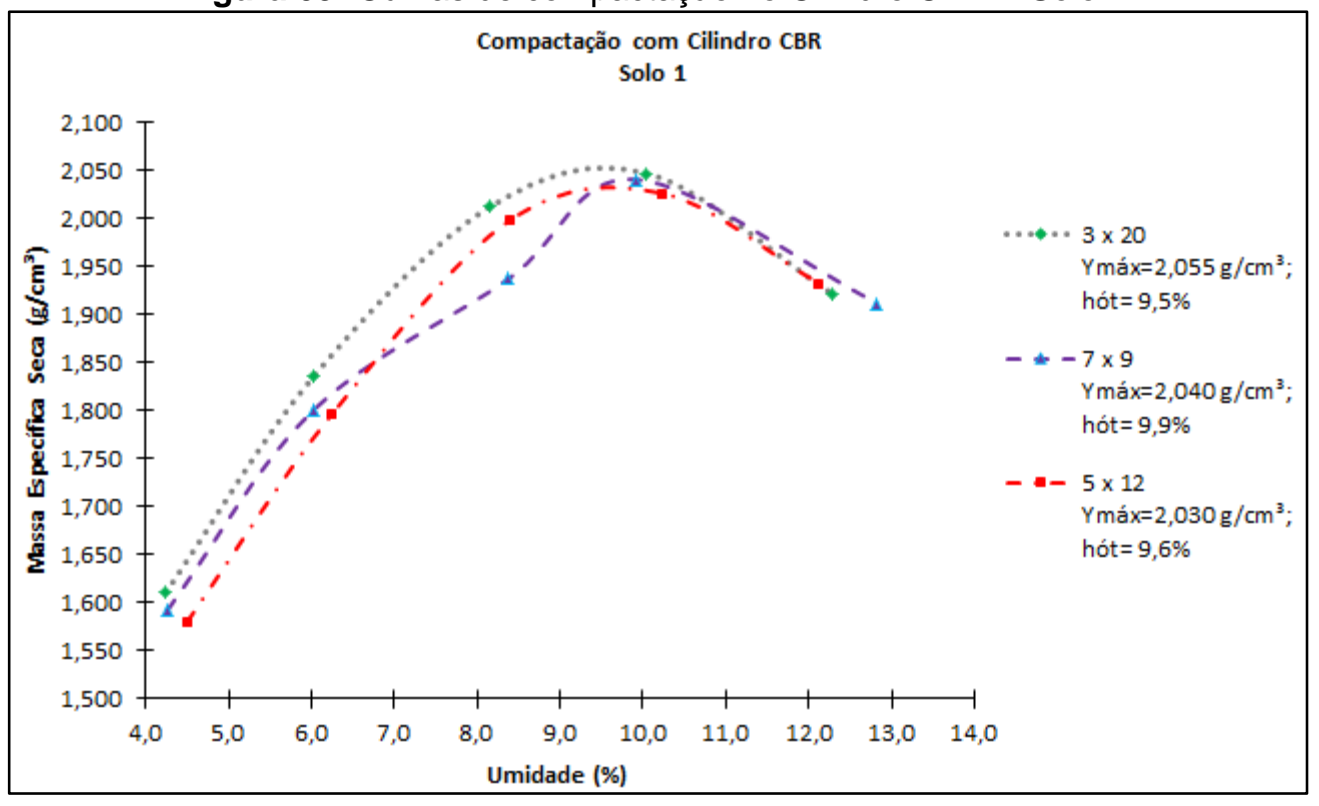

Fonte: Autores.

Como mostrado na Figura 9, em relação à compactação normal, houve um aumento na massa específica seca máxima do solo 1 através das variações. 0 método realizado com 3 camadas e 20 golpes por camada conferiu uma umidade ótima menor que a obtida pelo ensaio normal. A variação realizada com 7 camadas e 9 golpes, embora tenha proporcionado uma massa específica seca máxima superior à compactação normal, conferiu umidade ótima maior.

Figura 10: Curvas de compactação no cilindro CBR - Solo 2.

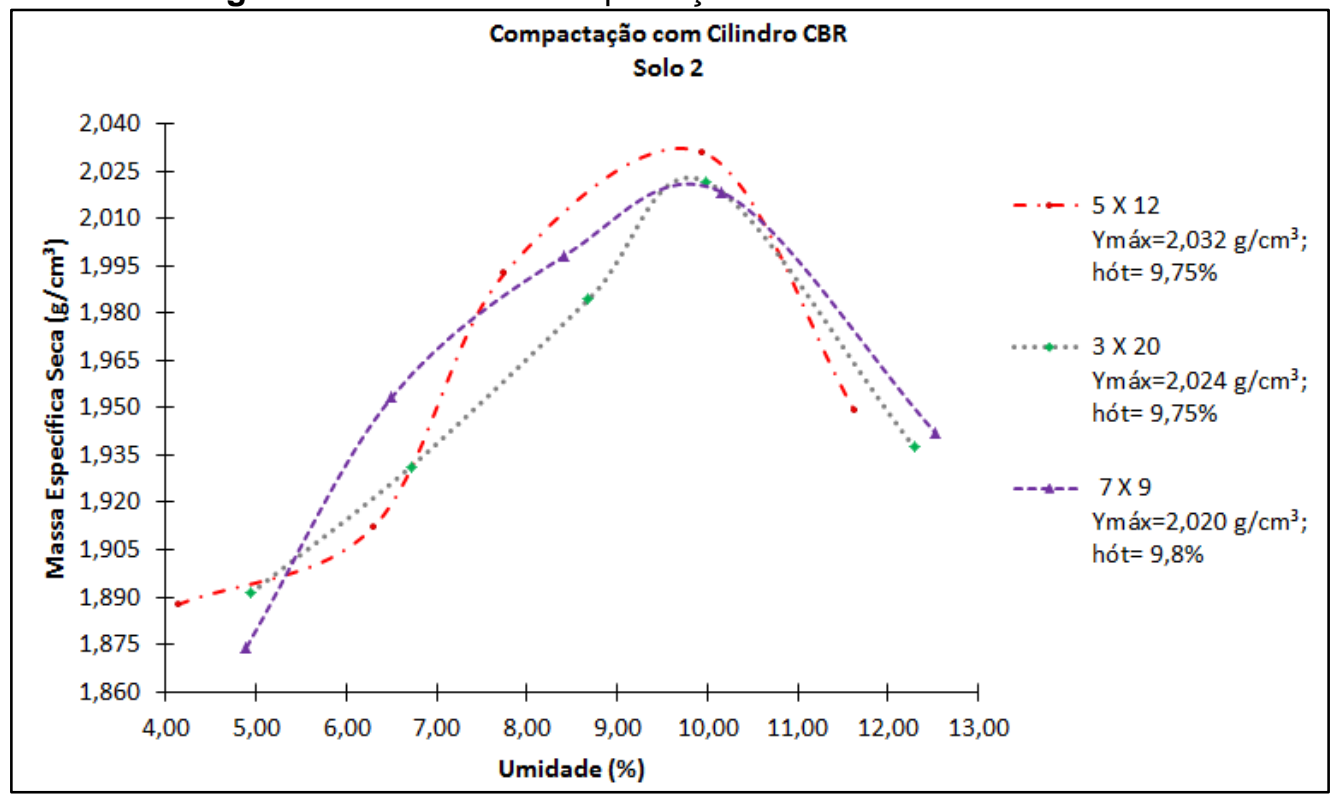

Fonte: Autores.

Para o solo 2, que é mais grosso que o solo 1, o ensaio Normal propicia massa específica máxima superior às variações de camadas realizadas no cilindro 
CBR, como mostrado na Figura 10. A umidade ótima das variações foram semelhantes à umidade ótima do procedimento normal.

Como é possível observar na Figura 11, para o solo 1, a variação do método realizado em 5 camadas e 9 golpes possibilitou obter-se uma massa específica máxima superior às demais variações de camadas realizadas no cilindro repartido, com uma umidade maior que o método de 3 camadas e 15 golpes e menor que a de 7 camadas e 7 golpes. $O$ mesmo método conferiu resultado melhor, quanto à massa específica, do que o melhor método realizado no cilindro CBR.

Figura 11: Curvas de compactação no Cilindro Repartido - Solo 1.

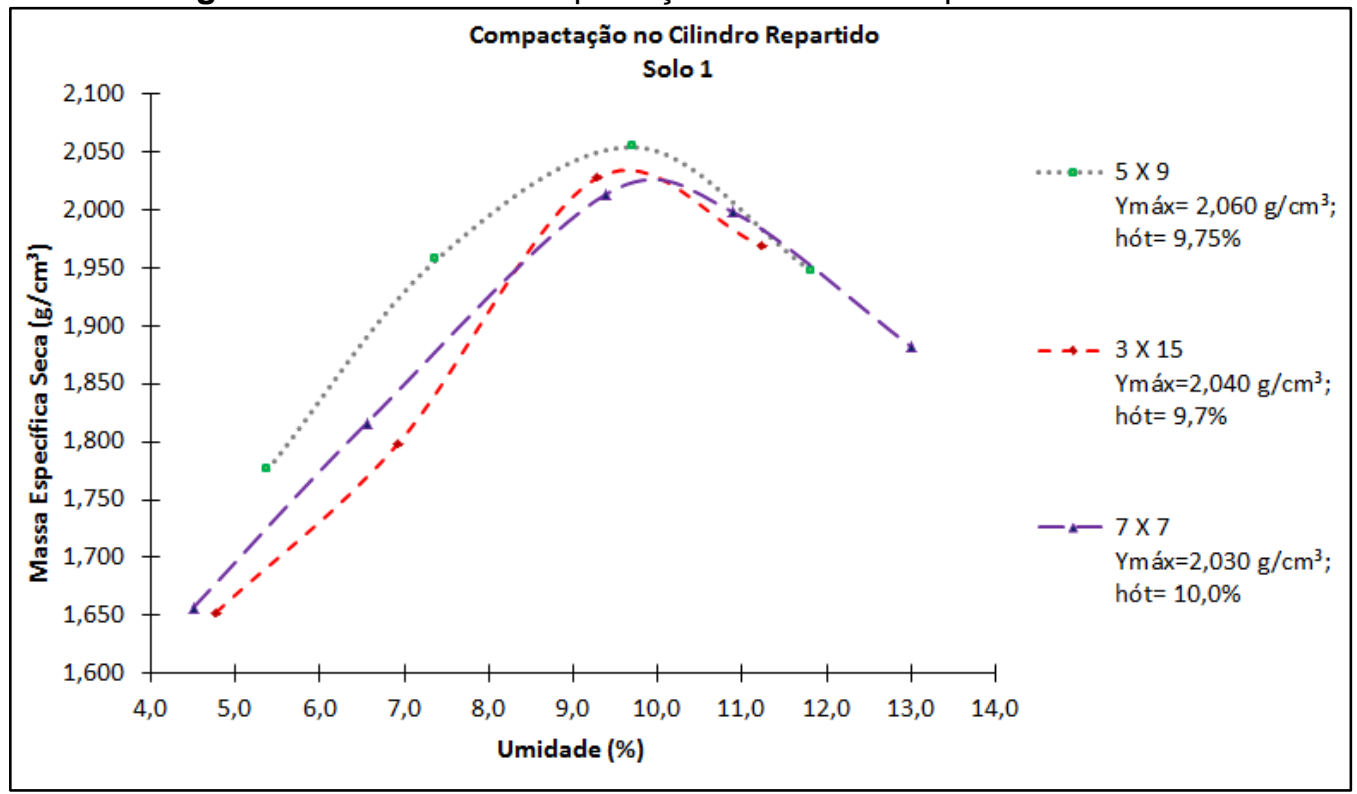

Fonte: Autores.

Para efeito de análise e comparação, os cilindros utilizados foram o Cilindro CBR e o Cilindro Repartido, sendo o primeiro utilizado na compactação de norma e a referência para o estudo.

Comparado ainda ao resultado obtido na compactação com o Cilindro CBR, o ensaio através do método de 3 camadas e 15 golpes no Cilindro Repartido apresenta valor de massa específica semelhante ao método de 7 camadas e 9 golpes.

Para o solo 2, no cilindro repartido (Figura 12), a variação de 5 camadas e 9 golpes conferiu maior massa específica, com umidade ótima também superior. Para esse tipo de solo, as variações realizadas no Cilindro CBR apresentaram valores de massa específica melhores que as variações realizadas no Cilindro Repartido, sendo Ciência e Sustentabilidade - CeS / Juazeiro do Norte, v. 4, n. 1, p. 156-177, jan/jun - 2018 
o ensaio realizado pela norma, com 5 camadas e 12 golpes o que garantiu a maior massa específica seca máxima para esse material.

Figura 12: Curvas de compactação no Cilindro Repartido - Solo 2.

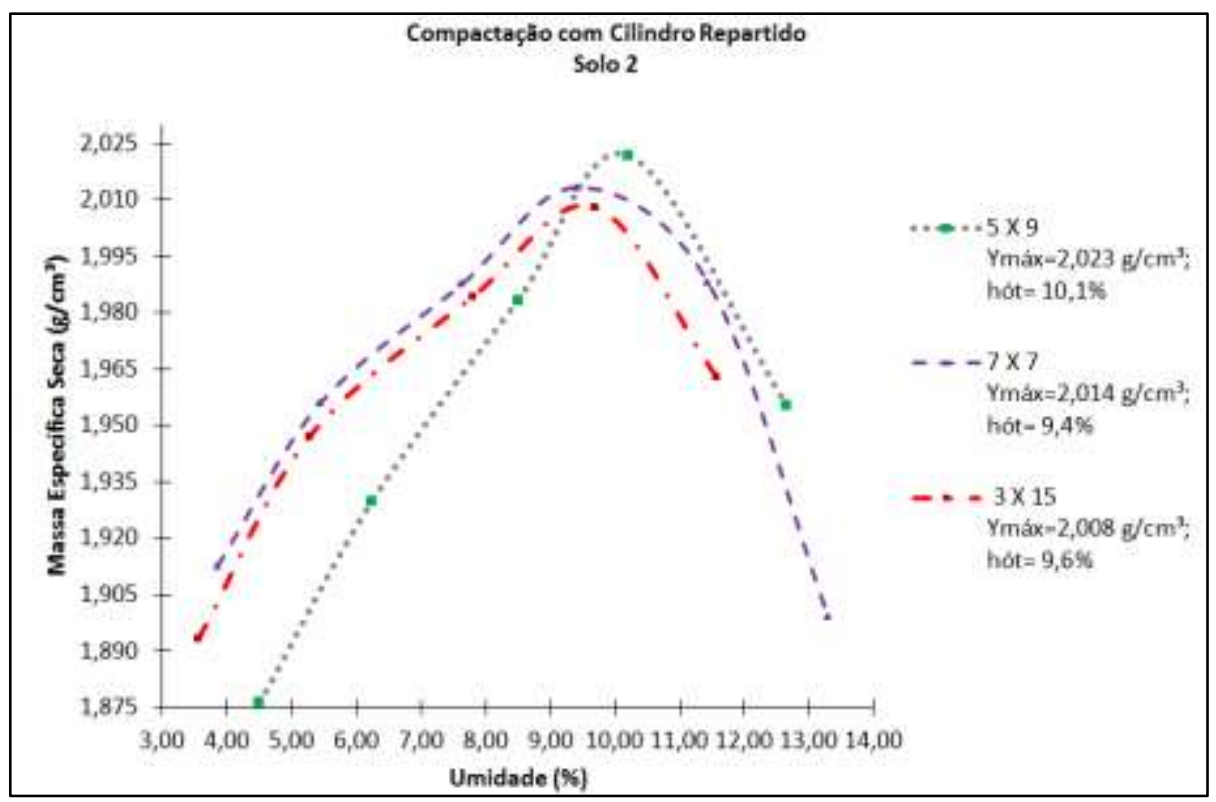

Fonte: Autores.

Os valores de massas especificas e suas respectivas umidades ótimas estão expressas nas Figuras 13 e 14 por ordem crescente de umidade, de acordo com o tipo de cilindro e o número de camadas, tendo-se uma visão geral de todos os métodos utilizados.

FIGURA 13: Determinações das Massas Específicas e Umidades Ótimas - Solo 1.

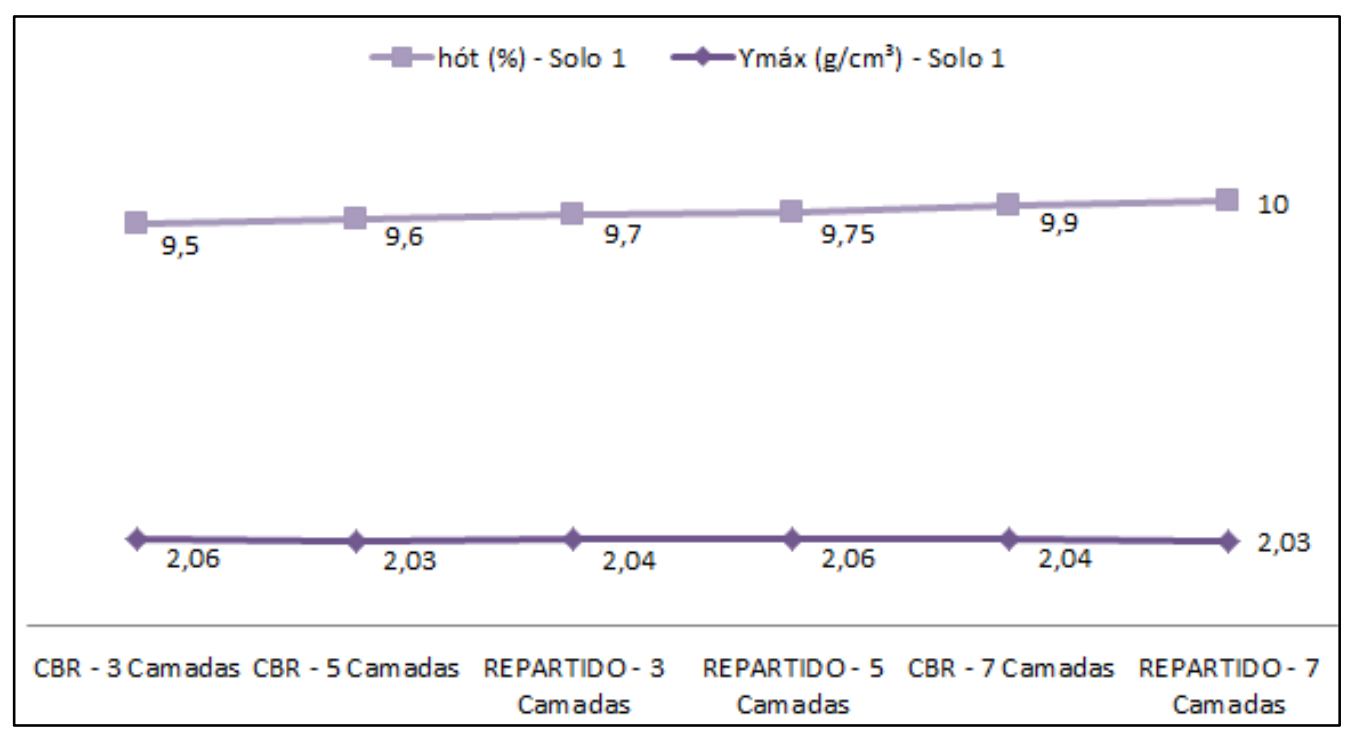

Fonte: Autores. 
Quanto ao número de camadas no cilindro $\mathrm{CBR}$, as variações realizadas no solo 1 resultaram em massas específicas superiores à compactação realizada por norma, sendo a melhor massa específica encontrada através do método realizado por 3 camadas e 20 golpes.

Quanto ao diâmetro do cilindro, a compactação no cilindro repartido realizado com 5 camadas e 9 golpes conferiu resultado semelhante à compactação com 3 camadas e 20 golpes no cilindro CBR, para o solo 1 . O método de 7 camadas e 7 golpes no Cilindro Repartido garantiu massa específica similar ao método Normal realizado no Cilindro CBR, bem como o método de 3 camadas e 15 golpes no cilindro Repartido se assemelhou ao método de 7 camadas e 9 golpes do cilindro CBR.

Quanto à umidade, o método de 3 camadas no cilindro CBR demonstrou que a menor umidade proporcionou a maior massa específica para o solo 1. A diferença de umidade para o método normal foi de 0,1\%, aparentemente insignificante. Porém, aplicando o exemplo a um empreendimento de uma rodovia de $13 \mathrm{~km}$, com um volume de aterro de $2.000 .000 \mathrm{~m}^{3}$ e umidade natural de $3 \%$, essa diferença percentual das umidades ótimas pode significar uma economia de 1.940 .000 litros de água, o que, tratada, poderia abastecer um edifício de 20 pavimentos com 4 apartamentos por andar e 4 pessoas em cada apartamento, durante 30 dias, considerando um consumo médio individual diário de 200 litros.

FIGURA 14: Determinações das Massas Específicas e Umidades Ótimas - Solo 2.

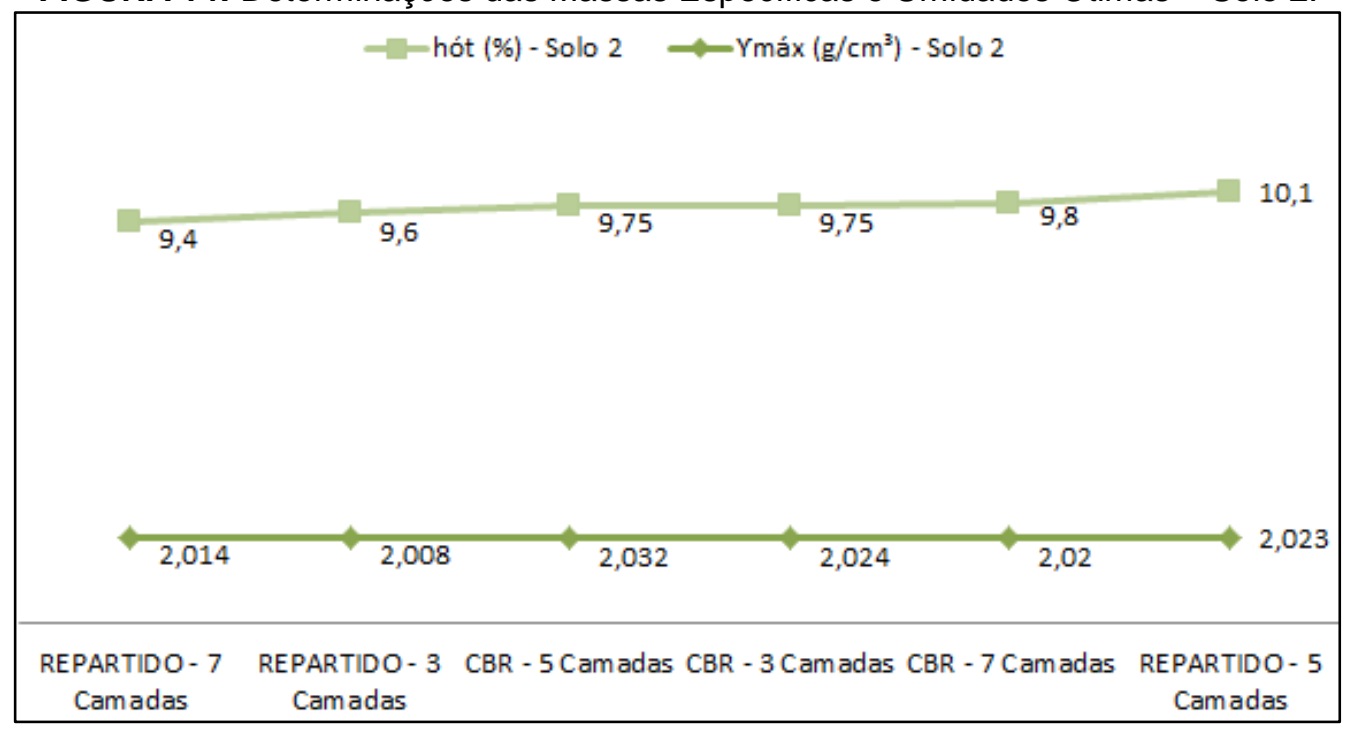

Fonte: Autores.

Ciência e Sustentabilidade - CeS / Juazeiro do Norte, v. 4, n. 1, p. 156-177, jan/jun - 2018 
Para o solo 2, a compactação normal no cilindro CBR propiciou a maior massa específica, com uma diferença decimais muito significativa às variações nas camadas. Não houve diferença relevante nos valores de massa específica seca máxima entre as duas variações, para esse cilindro.

No cilindro Repartido, obteve-se maior massa específica máxima pelo método de 5 camadas e 9 golpes, valor semelhante à compactação com 3 camadas e 20 golpes do cilindro CBR.

No entanto, todos os ensaios realizados conferiram massas específicas secas máximas semelhantes, seguindo um critério de discrepância de $5 \%$ da maior massa específica seca obtida, podendo, então, serem aceitos sem que haja perda significativa da massa específica seca máxima entre os métodos variando camadas e volume do cilindro.

Embora o solo tenha alcançado maior massa específica na compactação normal, o método de 7 camadas no cilindro Repartido demonstrou que pode ser feita a compactação com umidade menor, sem significativa diminuição da massa específica máxima, tomando o critério de discrepância adotado. A diferença de umidade foi maior que no solo 1 , representando $0,35 \%$, que pouparia cerca de 6.790.000 litros de água no mesmo empreendimento considerado para o solo 1, que abasteceria o mesmo edifício do exemplo anterior, durante 3 meses e meio.

\section{CONSIDERAÇÕES FINAIS}

Conclui-se que, o estudo foi importante para provar que novos métodos de compactação demonstram que os solos da região do Cariri, especificamente, podem ser compactados com uma umidade mais baixa que o método normal fornece, sem implicar significativamente na sua massa específica seca máxima. Isso gera uma economia considerável de recurso hídrico que está entrando em um quadro de escassez em algumas regiões do Brasil e do mundo, bem como a economia de dinheiro gasto na sua aquisição e seu transporte.

Portanto, para o solo 1, o método que melhor se adequa às condições acima levadas em consideração bem como o critério de aceitação de método de $5 \%$, é o de 3 camadas no Cilindro CBR, aplicando-se 20 golpes por camada. Para o solo 2, o 
melhor método baseado nas mesmas circunstâncias, é o de 7 camadas no cilindro Repartido, aplicando-se 7 golpes.

Como continuação de pesquisas, tem-se como sugestão 0 estudo comparativo entre compactações realizadas segundo as especificações NBR 162 "Solos - ensaio de compactação utilizando amostras trabalhadas" e NBR 164 "Solos - ensaio de compactação utilizando amostras não trabalhadas", a fim de obter o método que proporciona maior massa específica seca máxima ou menor umidade ótima, sem relevante redução da massa específica.

\section{REFERÊNCIAS}

ASSOCIAÇÃO BRASILEIRA DE NORMAS TÉCNICAS, NBR 7182: Solo - Ensaio de compactação. Rio de Janeiro, 1986.

CRISPIM, F. A. Compactação de solos: influência de métodos e de parâmetros de compactação na estrutura dos solos. Dissertação (Magister Scientiae) Universidade Federal de Viçosa. Viçosa, MG, 2007.

CRISPIM, F. A. Influência de variáveis de compactação na estrutura dos solos: caracterizações geotécnica, química, mineralógica e microestrutural. Tese (Doctor Scientiae) - Universidade Federal de Viçosa. Viçosa, MG, 2010.

DEPARTAMENTO NACIONAL DE ESTRADAS DE RODAGEM, ME 041/94: Solos preparação de amostras para ensaios de caracterização. Rio de Janeiro, 1994.

Janeiro, 1994.

ME 080/94: Solos - análise granulométrica por peneiramento. Rio de

ME 093/94: Solos - determinação da densidade real. Rio de Janeiro,

\section{4. \\ ME 162/94: Solos - ensaio de compactação utilizando amostras}

trabalhadas. Rio de Janeiro, 1994. 
DEPARTAMENTO NACIONAL DE INFRAESTRUTURA DE TRANSPORTES, 108/2009: Terraplenagem - Aterros - Especificação de serviço. Rio de Janeiro, 2009.

JUNIOR, J. D. S. O efeito da energia de compactação em propriedades dos solos utilizados na pavimentação do Estado do Ceará. Dissertação (Mestrado em Ciências em Engenharia de Transportes) - Universidade Federal do Ceará. Fortaleza, CE, 2005.

PEREIRA JUNIOR, M. S. ; RIBEIRO, A. J. A. . Análise das diferenças entre a compactação dos solos pelos métodos manual e mecânico. In: XI CONNEPI, 2016, Maceió - Alagoas. Anais, 2016.

PINTO, C. S. Curso Básico de Mecânica dos Solos. São Paulo, 2006.

PROCTOR, R.R., Fundamental Principles of Soil Compaction. Engineering News Record, 1933, pp. 20-28.

QUINTANS, A. L. L. Estudo das propriedades mineralógicas, físicas e mecânicas de um solo arenoso fino laterítico (SAFL) utilizado na pavimentação do complexo portuário da Grande Natal - RN/NE. Dissertação (Mestre em Engenharia Civil e Ambiental) - Universidade Federal de Campina Grande. Campina Grande, PB, 2008.

SOBREIRA, D. S. V. Comparação entre os métodos de compactação de solos por impacto e por amassamento. Dissertação (Mestre em Engenharia Civil e Ambiental) - Universidade Federal de Campina Grande. Campina Grande, PB, 2014.

WERK, S. M. S. Estudo da influência dos métodos de compactação no comportamento resiliente de solos. Dissertação (Mestre em Engenharia) Universidade Federal do Rio Grande do Sul. Porto Alegre, 2000. 